\title{
HAMMER IMPACT TEST APPLIED FOR FOULING DETECTION IN PIPELINES
}

\author{
Jaidilson Jó da Silva* \\ jaidilson@dee.ufcg.edu.br \\ Franz Helmut Neff* \\ neff@dee.ufcg.edu.br
}

\author{
Antonio Marcus Nogueira Lima* \\ amnlima@dee.ufcg.edu.br \\ José Sérgio da Rocha Neto* \\ zesergio@dee.ufcg.edu.br
}

*Universidade Federal de Campina Grande

Departamento de Engenharia Elétrica

Av. Aprigio Veloso 882 - CEP 58429-900, Campina Grande, Paraíba, Brazil

\section{RESUMO}

Teste de Impacto do Martelo aplicado na Detecção de Incrustação em Tubulações

A detecção da incrustação em sistemas de dutos é um problema persistente e requer uma demanda pertinente para as indústrias químicas, petrolíferas, alimentícias e farmacêuticas. A incrustação é um processo de deposição de materiais sólidos dissolvidos orgânicos e outros materiais pesados nos fluidos transportados ou em suspensão sobre as superfícies das paredes internas em sistemas de transporte de fluidos. Este trabalho apresenta resultados da pesquisa de excitação do teste do martelo para análise de vibrações utilizando testes não-invasivos para detecção de incrustação em tubulações. Dados da vibração foram analizados na presença de uma camada de incrustação no interior dos tubos usando um acelerometro e um microfone para detecção. Com a análise dos resultados obtidos é possível detectar o processo de incrustação, nas tubulações monitoradas, com e sem condições de carga, utilizando um microfone e um acelerômetro como sensores.

PALAVRAS-ChaVE: Análise de vibrações, Teste do impacto do martelo e Detecção da incrustação.

Artigo submetido em 10/03/2011 (Id.: 01295)

Revisado em 06/07/2011, 09/08/2011, 29/09/2011

Aceito sob recomendação do Editor Associado Prof. Carlos Roberto Minussi

\section{ABSTRACT}

The fouling detection in duct systems is a persistent problem and remains a relevant demand for the chemical, oil, food and pharmaceutical industries. The fouling is a deposition process of heavy organic and other dissolved solid materials in the transported fluids or suspensions onto inner wall surfaces in fluid transport systems. This work presents research results of hammer test for vibration analysis using non-invasive tests to fouling detection in pipelines. Data were taken from the vibration in presence of an inner pipe fouling layer using an accelerometer and a microphone for detection. With the analysis of the obtained results is possible to detect the fouling process, in the monitored pipelines, with and without load conditions, using a microphone and an accelerometer as sensors.

KEYWORDS: Vibrations analysis, Hammer impact test and Fouling detection.

\section{INTRODUCTION}

A problem related to transporting fluid material through pipelines is the accumulation of organic or inorganic substances in their internal surfaces with time. Such accumulation of unwanted material is denoted fouling and it has been studied mainly in the chemical, petroleum, food and pharmaceutical industries, due to 
technical difficulties which may appear in these processes (Rose, 1995), (Branco et al., 2001) and (Cam et al., 2002). Fouling in ducts causes several severe problems such as: the reduction of the internal diameter of the pipeline; the required increase of the applied pressure to maintain through-put can cause crack formation and possibly catastrophic breakup, the associated increase of the energy consumption also comes along with higher operation and maintenance costs (Mansoori, 1997) and (Escobeto et al., 1997).

Large industrial crude oil refining/processing plants are designed as complex tubing structures, with up to several kilometers of interconnected tubes. It therefore is quite difficult and work intensive to quickly and safely identify, exactly localize, clean or replace critical tube sections, to avoid or reduce plant shut down times (Mansoori, 2001).

Several methods have been proposed for fouling detection, based on mass flow reduction, electric resistance sensors and ultrasonic techniques (Krisher, 2003), (Panchal, 1997), (Hay and Rose, 2002), (Gatts et al., 2004), (Barshinger and Rose, 2002) and (Lohr and Rose, 2002). Tests with hammer impact have been used before in numerous engineering areas to analyze frequency response functions (FRF), due to convenience and simplicity of the experiments, as well as the validity of the analysis procedures (Castelline et al., 2004), (Roy and Ganesan, 1995), (Nahvi and Jabbari, 2005), (Shen and Pierre, 1994), (Carino, 2001) and (Silva et al., 2010a).

In (Silva et al., 2009a) are presented initial results with the hammer impact test, just using a microphone for acoustic analysis of the signals, for fouling detection. In (Silva et al., 2009b) are presented the result analysis of different layers of fouling, inside the tube, using acoustic and vibrations analysis for tests without load conditions, in other words, without liquid inside the tubes. In (Silva et al., 2010b) are presented results of tests with vibration analysis for fouling detection, emphasizing the use of finite elements and verification of the results for tests without load conditions.

In this work, we presented the results of the acoustic analysis, using a microphone as sensor, and vibration analysis using an accelerometer as sensor. These tests are performed under load conditions, in other words, with liquid inside the tubes, emphasizing the differences in the tests. Also, were performed the tests in a real pipe, used in the petroleum transport, for fouling detection with acoustic and vibration analysis.

\section{PROPOSED METHOD}

The physical principle is simple: when the tube is mechanically excited by hammer impact, a relatively localized area of the tube section begins to vibrate at acoustic frequencies for a certain period of time at one or more resonance frequencies. The vibration propagates as a very fast acoustic wave within the duct wall, and as a surface wave. The latter couples to the environmental air and is detected by a closely mounted microphone and accelerometer. Due to internal damping, the hammer excited vibration attenuates rapidly. The temporal development and decay of the free vibration depends on the physical characteristics of the system/pipe geometry, especially of the damping coefficient (Ahn and Jeong, 2005), which is determined by the wall thickness.

During the impact phase, the system is represented as a joining between the hammer and the structure. At the end of the impact, the hammer looses the contact with the structure, which now vibrates freely in agreement with their natural resonance frequencies (Champoux et al., 2003).

Based on ideas presented earlier, the acoustic hammer impact has been evaluated in this work towards simplified fouling detection in ducts and pipelines, used for crude oil transport. Here, we analyze variations in vibration amplitude and frequency using accelerometer and microphone output signals in the presence of inner tube fouling layers.

A fouling detector has been exploited, using the hammer test to provoke mechanical vibrations in the pipe section under investigation. An excitation system is used to generate vibrations in the pipe section under test. A detection system for signal conditioning is used to record the vibration parameters. The signals are analyzed in time and frequency domain using an oscilloscope and a spectrum analyzer.

Figure 1 represents a sketch of the experimental set-up using a microphone and an accelerometer as sensors. 


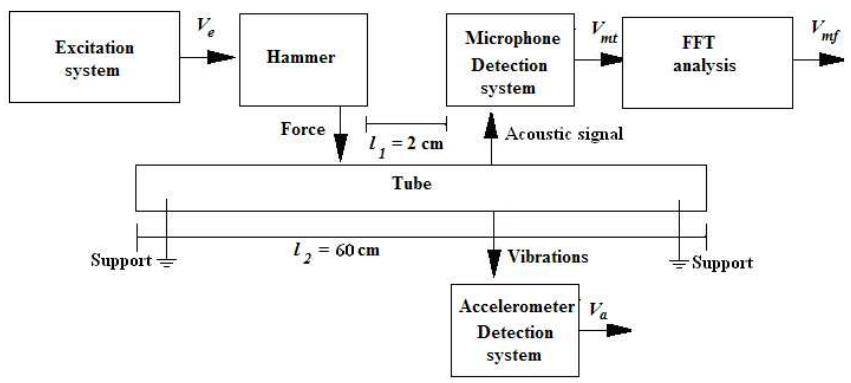

Figure 1: Sketch of the experimental set-up with microphone and accelerometer.

The electromagnetic displacement system is formed by a DC power supply and for a pulse generator, that excites a coil and it activate the hammer, making the hammer to hit the pipe. The hammer excitation signal frequency is controlled for the pulse generator. The sample rate of the data acquisition is $200 \mathrm{MHz}$ and the force impact has a repeatability of $2 \mathrm{~Hz}$, this frequency is used to control the repeatability of the hammer impact onto the tube. The applied force onto surface of the test tube was $0.4 \mathrm{~N}$, as determined by a digital dynamometer, well maintaining the impact load magnitude.

The test tube comprises a wall thickness of $2.5 \mathrm{~mm}$, a diameter of $10 \mathrm{~cm}$, a length of $60 \mathrm{~cm}\left(l_{2}\right)$, made from galvanized iron.

In all tests the same pipes are used. Initially the tests are performed with the microphone and later with the accelerometer to avoid errors. The tests are performed with metal tubes, because the objective is the fouling detection in the petroleum transport.

The variation in temperature influences in the fouling process, but the microphone and accelerometer, which are used as sensors, can still detect the modifications in the acoustic and vibration signals. If the temperature decreases, the fouling process increases, because the present substances in the liquid will crystallize in a faster way. If the temperature increases, the fouling process decreases, because the thermal agitation of the molecules increases (Escobeto et al., 1997), (Mansoori, 1997), (Mansoori, 2001).

The methodology relies on observing the parameters: amplitude, decay time and frequency, in the monitored signals.

\subsection{Tests with the accelerometer}

A sketch of the accelerometer output signal is presented in Figure 2, according to (Silva, 2008).
We can define the following expression for the maximum amplitude of the signal $V_{a}(t)$ :

$$
A_{i}=\max \left(V_{a}(t)\right), i=1,2, \ldots, N
$$

where: $e_{i}$ is the fouling thickness $\left(e_{2}>e_{1}\right), V_{a}(t)$ is the output signal of the detection system using the accelerometer and $A_{i}$ is the maximum amplitude of the signal $V_{a}(t) . T$ is the repetition rate in the tests.

The mean value $(A)$ for the maximum amplitude of the signal $V_{a}(t)$ is:

$$
A(e)=\frac{1}{N} \sum_{i=1}^{N} A_{i}(e)
$$

where: $N$ is the number of tests used in each experiment.

The increase in the fouling thickness $(e)$ provokes a reduction in the amplitude maximum value in the output signal $\left(A_{i}\right)$.

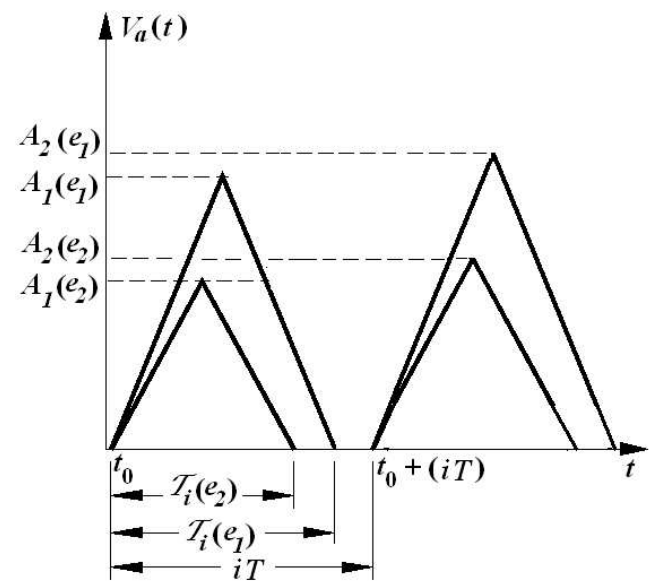

Figure 2: Representation of the signal in the accelerometer output.

\subsection{Tests with the microphone in time do- main}

A sketch of the attenuated microphone output signal in the time domain is presented in Figure 3, according to (Silva, 2008).

We can define the following expression for the envelope of the signal $V_{m t}(t)$ :

$$
P(t)=P_{0}\left(1-e^{-\frac{t}{d_{i}(e)}}\right)
$$


where: $e_{i}$ is the fouling thickness $\left(e_{2}>e_{1}\right), V_{m t}(t)$ is the output signal of the detection system using the microphone, in time domain, $P(t)$ is the envelope signal and $d_{i}$ is the decay time of the signal $V_{m t}(t)$, in other words, the necessary time to reduce the maximum amplitude $\left(P_{0}\right)$ of the signal $V_{m t}(t)$ for $37 \%$ of its value $\left(\left(1-e^{-1}\right) P_{0}\right)$.

The mean value $(D)$ for the decay time of the signal $V_{m t}(t)$ is:

$$
D(e)=\frac{1}{N} \sum_{i=1}^{N} d_{i}(e)
$$

where: $N$ is the number of tests used in each experiment.

The increase in the fouling thickness $(e)$ provokes a reduction in the value of the decay time $\left(d_{i}\right)$ of the signal $V_{m t}(t)$.

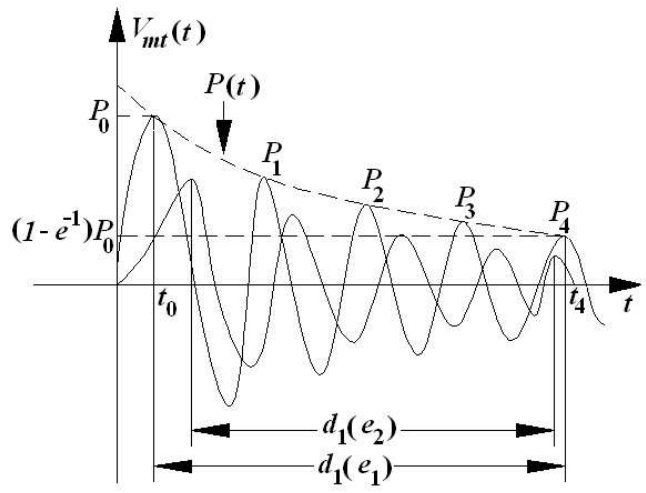

Figure 3: Representation of the signal in the microphone output, in time domain.

\subsection{Tests with the microphone in frequency domain}

A sketch of the attenuated microphone output signal in the frequency domain is presented in Figure 4, according to (Silva, 2008).

We can define the following expression for the resonance frequency of the signal $V_{m f}(f)$ :

$$
f_{\text {resi }}=\operatorname{argmax}\left(V_{m f}(f)\right), f \in\left[f_{0}, f_{1}\right]
$$

where: $e_{i}$ is the fouling thickness $\left(e_{2}>e_{1}\right), V_{m f}(f)$ is the output signal of the detection system using the microphone, in frequency domain, and $f_{\text {resi }}$ is the resonance frequency of the signal $V_{m f}(f)$, in other words, the frequency $(f)$ where occur the maximum value $\left(V_{i}\right)$ of the signal $V_{m f}(f)$.

The mean value $(F)$ for the resonance frequency of the signal $V_{m f}(f)$ is:

$$
F(e)=\frac{1}{N} \sum_{i=1}^{N} f_{r e s i}(e)
$$

where: $N$ is the number of tests used in each experiment.

The increase in the fouling thickness $(e)$ provokes a reduction in the value of the resonance frequency $\left(f_{\text {resi }}\right)$ of the signal $V_{m f}(f)$.

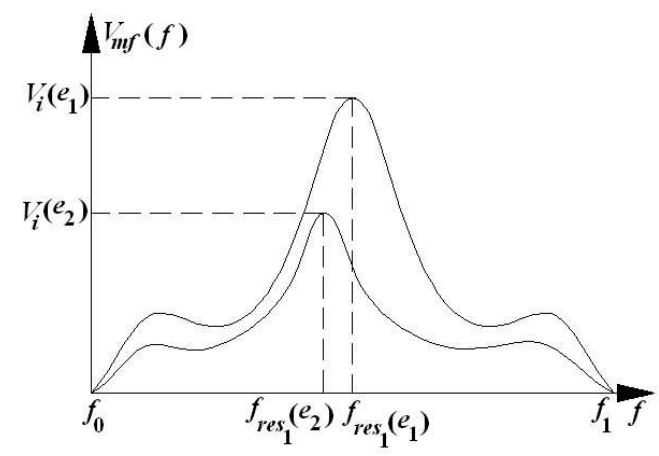

Figure 4: Representation of the signal in the microphone output, in frequency domain.

\section{EXPERIMENTAL RESULTS}

A calibration step to define the original acoustic tube signature is initially carried out in absence of a fouling layer. The received signal is monitored, and the acoustic features (amplitude, frequency) stored as reference.

The originally present asphaltic fouling layer has been replaced by a paraffin (resin) film with varying thickness up to $10 \mathrm{~mm}$, carefully deposited within the test tubes.

A commercial MEMS accelerometer sensor from Ana$\log$ Devices ADXL 202 and a high quality microphone from Sennheiser Cardioid GM 580 (Bandwidth: $50 \mathrm{~Hz}$ to $13 \mathrm{kHz}$ ) have been employed for the investigations. The MEMS detector has been glued onto the tube circumference at a distance of $2 \mathrm{~cm}\left(l_{1}\right)$ from the hammer impact point. The microphone has been mounted at the same distance. 


\subsection{Tests with microphone (pipes without water)}

The obtained signals, in the frequency domain, for the pipes without water are presented in Figures 5, 6 and 7 .

Associate signals, in time domain, for the pipes without water are presented in Figures 8, 9 and 10.

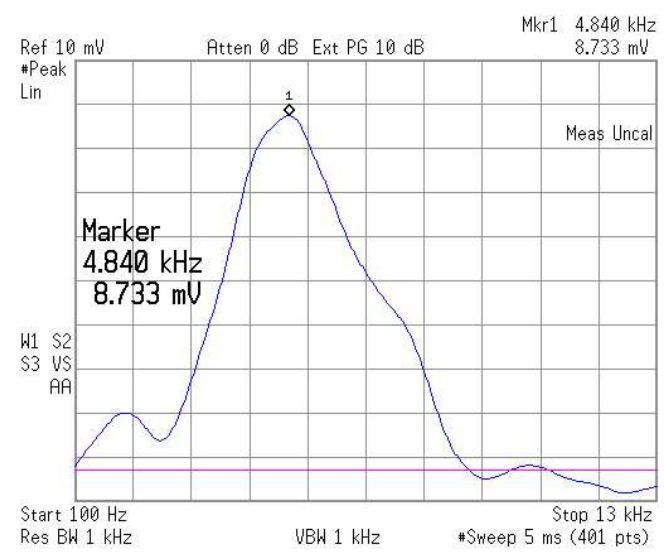

Figure 5: Representation of the microphone output signal for the tube without fouling.

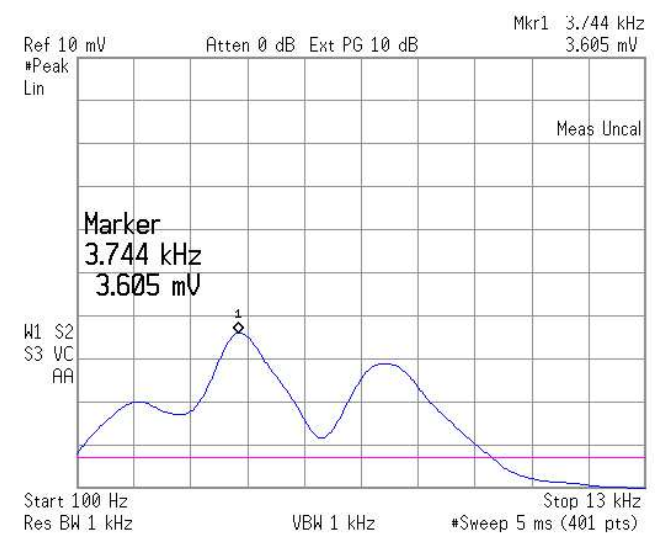

Figure 6: Representation of the microphone output signal for the tube with $5 \mathrm{~mm}$ of fouling.

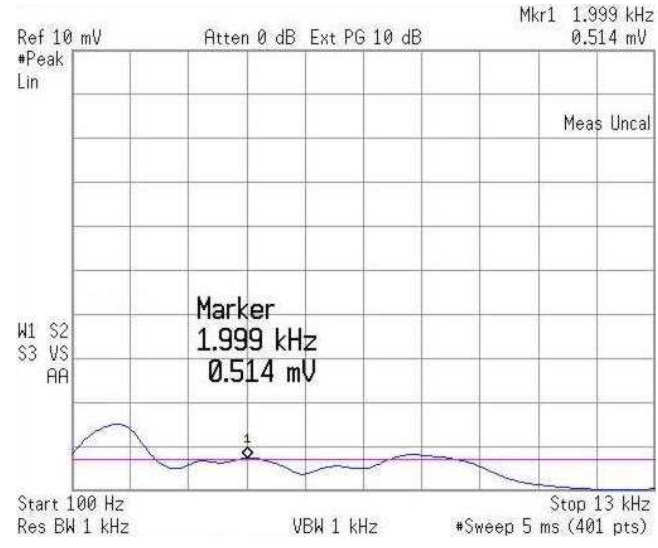

Figure 7: Representation of the microphone output signal for the tube with $10 \mathrm{~mm}$ of fouling.

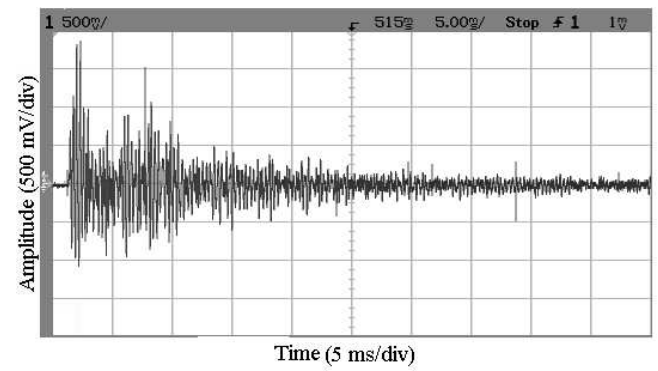

Figure 8: Representation of the microphone output signal, in time domain, for the tube without fouling.

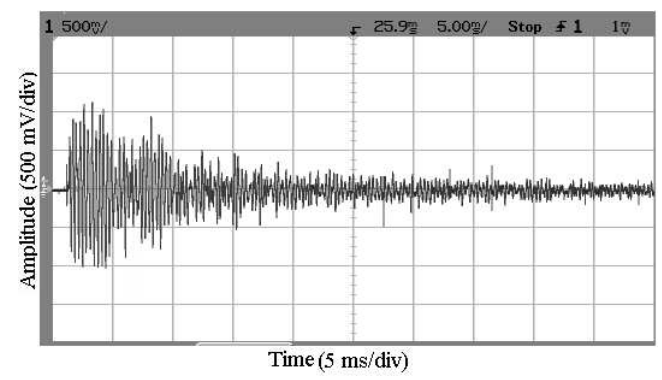

Figure 9: Representation of the microphone output signal, in time domain, for the tube with $5 \mathrm{~mm}$ of fouling. 


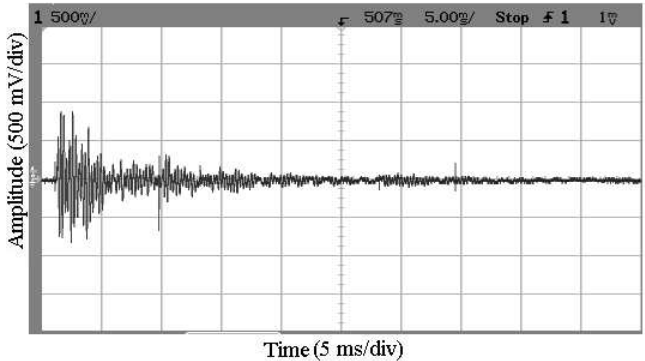

Figure 10: Representation of the microphone output signal, in time domain, for the tube with $10 \mathrm{~mm}$ of fouling.

The decay time for the tube without fouling is $14 \mathrm{~ms}$, for $5 \mathrm{~mm}$ of fouling is $10 \mathrm{~ms}$ and for $10 \mathrm{~mm}$ of fouling is $5 \mathrm{~ms}$.

Analysing the results, we can observe that the reduction in frequency and decay time, in relation to clean tube, are the indicative of presence and increase of fouling in the monitored pipelines.

The microphone records the acoustic tube signature, due to excitation and propagation of a longitudinal wave, as known from the ringing bell.

\subsection{Tests with accelerometer (pipes with- out water)}

The monitored and stored accelerometer output signals, for the pipes without water, are illustrated in the upper traces of Figures 11, 12 and 13 in absence of fouling, for fouling layer thickness of $5 \mathrm{~mm}$ and for fouling layer thickness of $10 \mathrm{~mm}$, respectively.

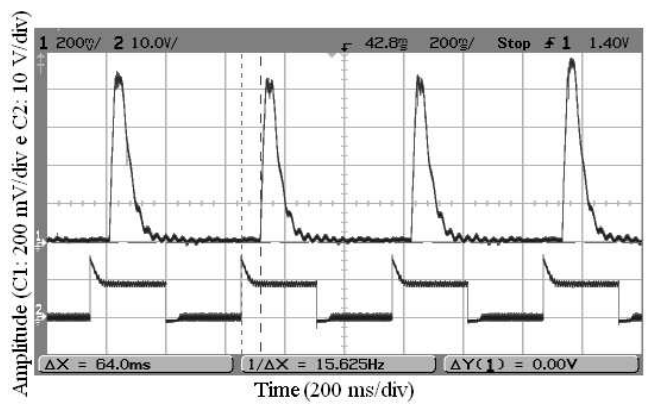

Figure 11: Accelerometer output signals in absence of fouling.

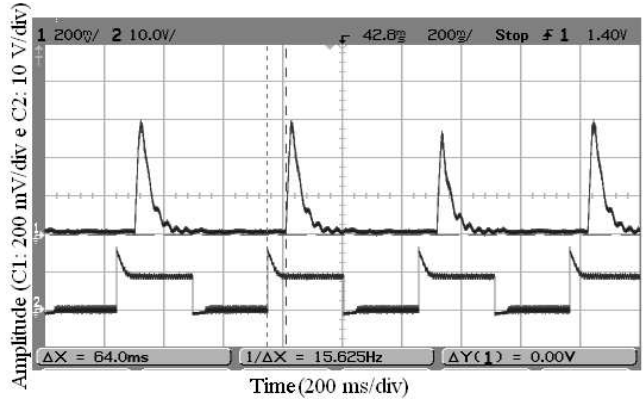

Figure 12: Accelerometer output signals with $5 \mathrm{~mm}$ of fouling.

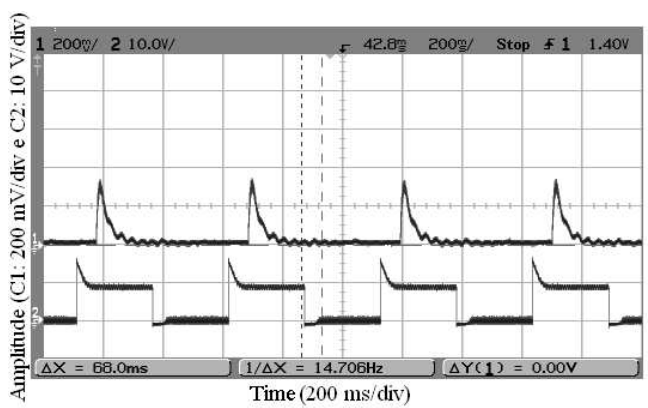

Figure 13: Accelerometer output signals with $10 \mathrm{~mm}$ of fouling.

With increasing film thickness the signal magnitude are decreasing. Persistent low magnitude ringing, observable in all time signals, most likely originates from a resonance in the MEMS accelerometer itself, where its spring type cantilever design supports the oscillating (vibration) response characteristic.

We attribute the origin of the signature recorded by the accelerometer to the transversal deformation wave, which propagates along the tube surface, similar to spreading of a surface water wave. This explanation is supported by our simulation, where the hammer impact causes spatially distributed surface deformations.

\subsection{Tests with microphone (pipes with wa- ter)}

Tests under loading conditions, in presence of water, in the tubes were also carried out with microphone. Figures 14 and 15 present the results, in frequency domain, for the tubes without fouling and with $5 \mathrm{~mm}$ of fouling. 


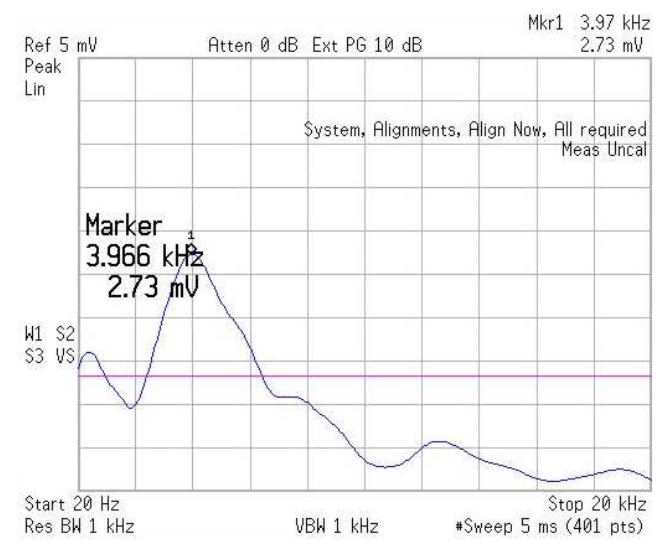

Figure 14: Representation of the microphone output signal for the tube without fouling (pipe with water).

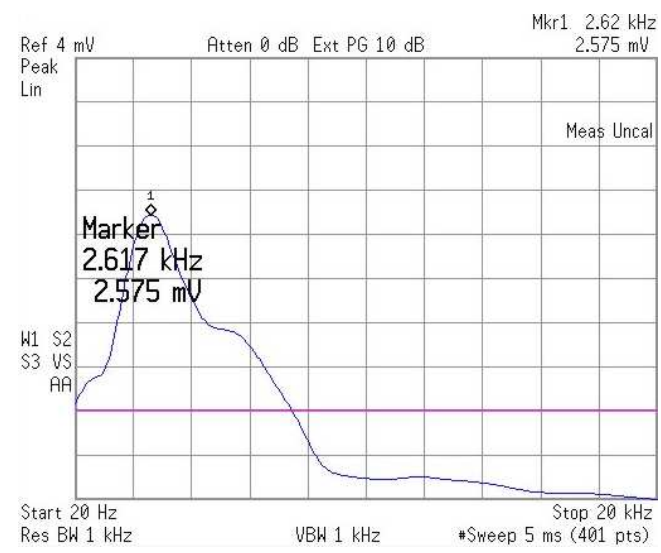

Figure 15: Representation of the microphone output signal for the tube with $5 \mathrm{~mm}$ of fouling (pipe with water).

Figures 16 and 17 present the results (pipes with water), in time domain, for the tubes without fouling and with $5 \mathrm{~mm}$ of fouling.

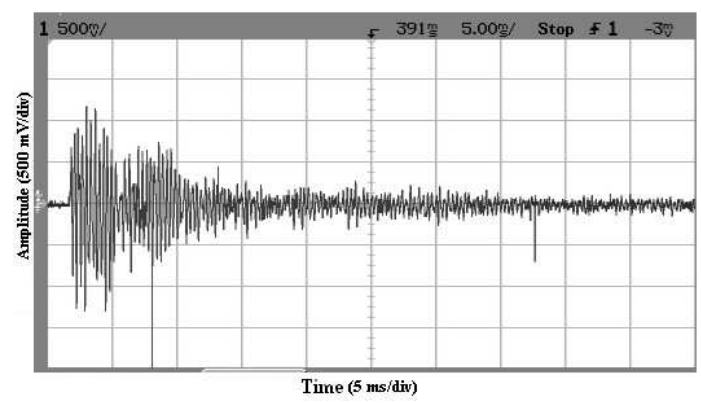

Figure 16: Representation of the microphone output signal, in time domain, for the tube without fouling (pipe with water).

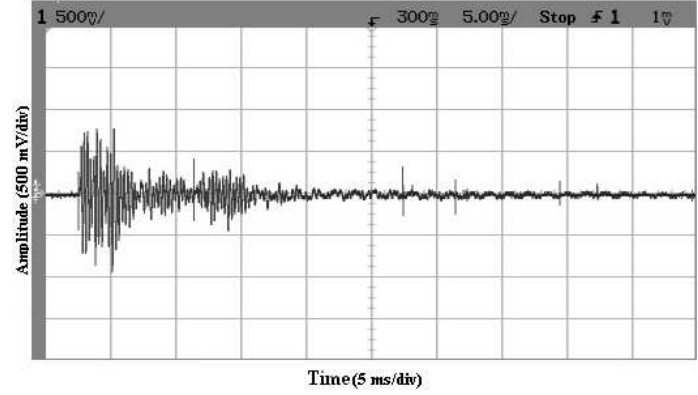

Figure 17: Representation of the microphone output signal, in time domain, for the tube with $5 \mathrm{~mm}$ of fouling (pipe with water).

The reduction of the resonance frequencies and decay times still allows fouling detection.

\subsection{Tests with accelerometer (pipes with water)}

Tests under loading conditions, in presence of water, in the tubes were also carried out with accelerometer. Figures 18 and 19 present the results, for the tubes without fouling and with $5 \mathrm{~mm}$ of fouling.

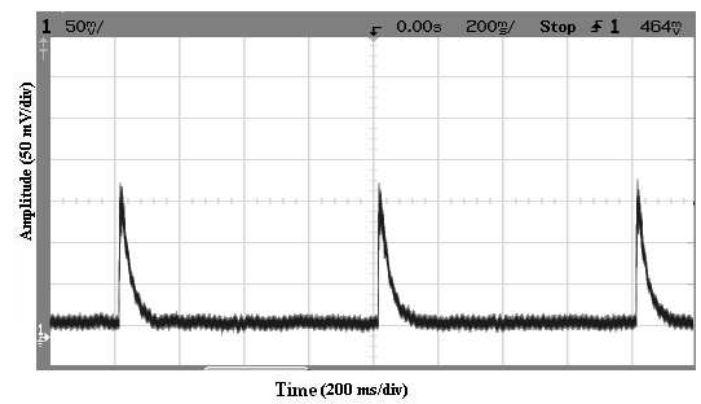

Figure 18: Accelerometer output signals in absence of fouling (pipe with water).

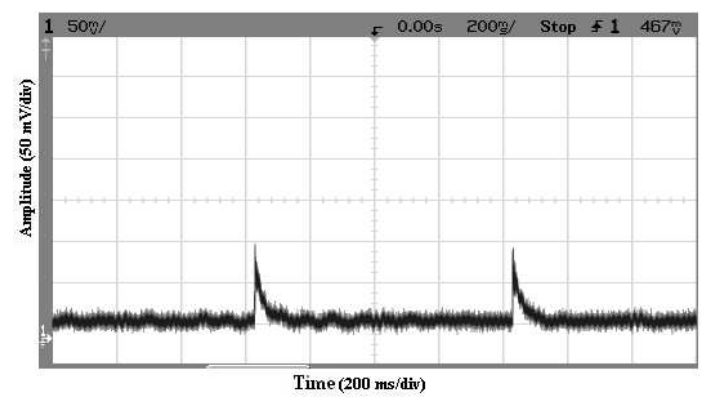

Figure 19: Accelerometer output signals with $5 \mathrm{~mm}$ of fouling (pipe with water). 
The reduction of the amplitudes still indicates fouling condition.

\subsection{Comparisons between the results with and without load conditions}

In Tables 1, 2 and 3 are presented the obtained results in the tests with and without liquid (water) inside the tubes. Tables 1 and 2 present the obtained results with microphone, in frequency domain and time domain, respectively. Table 3 presents the obtained results with accelerometer.

Table 1: Obtained results with microphone, in frequency domain.

\begin{tabular}{|c|c|c|}
\hline Fouling layer & $\begin{array}{c}\text { Tests with } \\
\text { water }\end{array}$ & $\begin{array}{c}\text { Tests without } \\
\text { water }\end{array}$ \\
\hline $0 \mathrm{~mm}$ & $4.84 \mathrm{kHz}$ & $3.97 \mathrm{kHz}$ \\
\hline $5 \mathrm{~mm}$ & $3.74 \mathrm{kHz}$ & $2.62 \mathrm{kHz}$ \\
\hline
\end{tabular}

Table 2: Obtained results with microphone, in time domain.

\begin{tabular}{|c|c|c|}
\hline Fouling layer & $\begin{array}{c}\text { Tests with } \\
\text { water }\end{array}$ & $\begin{array}{c}\text { Tests without } \\
\text { water }\end{array}$ \\
\hline $0 \mathrm{~mm}$ & $14.0 \mathrm{~ms}$ & $9.0 \mathrm{~ms}$ \\
\hline $5 \mathrm{~mm}$ & $10.0 \mathrm{~ms}$ & $4.0 \mathrm{~ms}$ \\
\hline
\end{tabular}

Table 3: Obtained results with accelerometer.

\begin{tabular}{|c|c|c|}
\hline Fouling layer & $\begin{array}{c}\text { Tests with } \\
\text { water }\end{array}$ & $\begin{array}{c}\text { Tests without } \\
\text { water }\end{array}$ \\
\hline $0 \mathrm{~mm}$ & $900 \mathrm{mV}$ & $170 \mathrm{mV}$ \\
\hline $5 \mathrm{~mm}$ & $600 \mathrm{mV}$ & $100 \mathrm{mV}$ \\
\hline
\end{tabular}

In load conditions (with water inside the tubes), the mass of the system is increased and the impact of the hammer provokes vibrations with smaller amplitudes and smaller acoustic levels which are detected by the accelerometer and microphone, respectively.

The hammer impact force should be determined according to the pipe dimension variations and the type of transported liquid, so that the levels of the monitored signals can indicate the fouling layers inside the tubes. Therefore, it is important to determine the pipe signature to perform the tests.

The properties of the transported liquid, as density, influence in the tests, because the force of the impact should be determined to guarantee the measurement of the parameters and their variations with the increase of the fouling.

\subsection{Tests with different layer of fouling}

In this case, tests were performed using the accelerometer and microphone, with signals in frequency domain, because the analysis of the results can be made directly starting from the observed signals.

Figure 20 presents a transverse view of the tube with three layer of fouling $(0 \mathrm{~mm}, 5 \mathrm{~mm}$ and $10 \mathrm{~mm})$.

Measurements were performed with distances, between the hammer impact and the accelerometer and microphone, of $3 \mathrm{~cm}$ along the tube. The obtained results with the accelerometer are presented in Figure 21.

The obtained results with the microphone are presented in Figure 22.

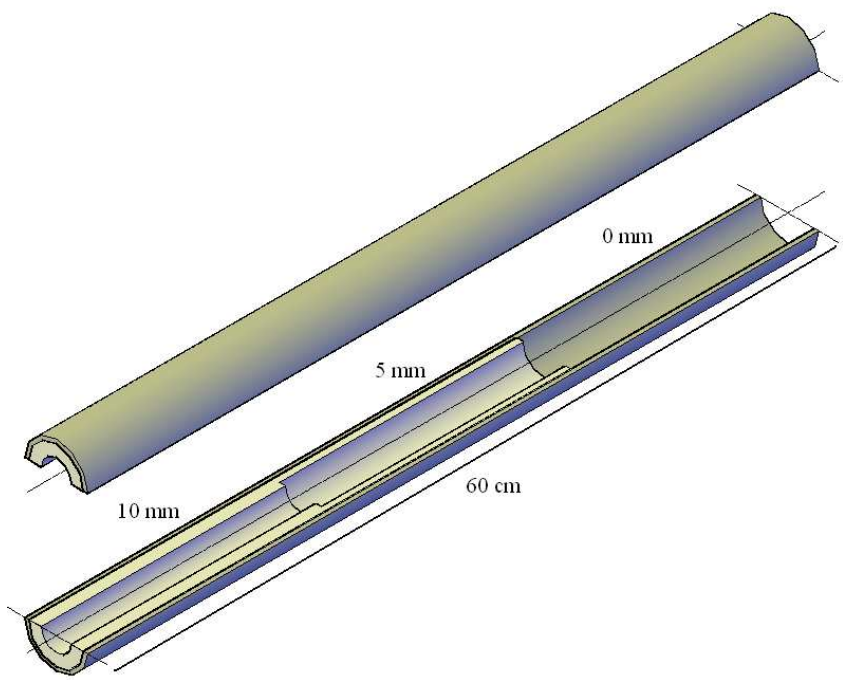

Figure 20: Transverse view of the tube with three layer of fouling with: $0 \mathrm{~mm}, 5 \mathrm{~mm}$ and $10 \mathrm{~mm}$ of resin.

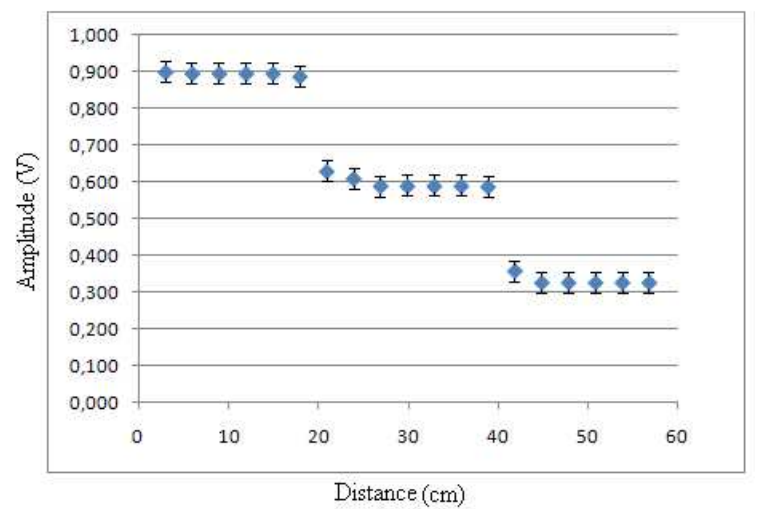

Figure 21: Obtained results with the accelerometer in a tube with multi-layer fouling. 


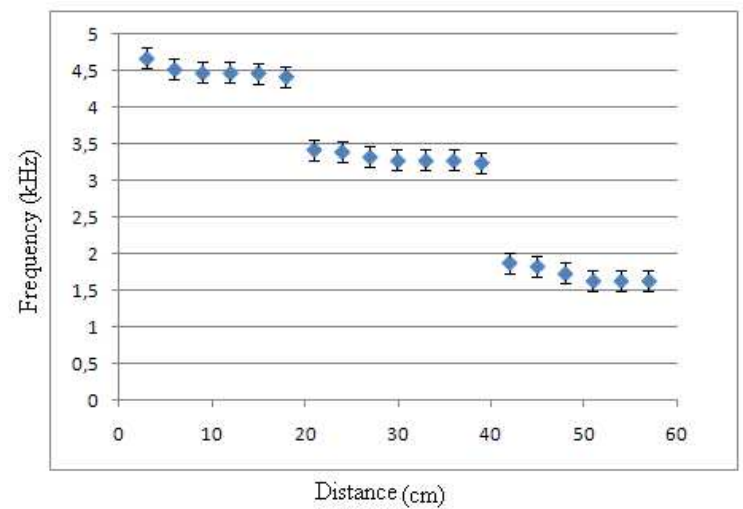

Figure 22: Obtained results with the microphone in a tube with multi-layer fouling.

With the increase of the fouling, there is a reduction in the amplitude, in the tests with the accelerometer. It is also observed the different levels of signals along the tube, that make possible to distinguish the layers inside the tube, in other words, clean tube up to $20 \mathrm{~cm}$, tube with $5 \mathrm{~mm}$ of fouling between 20 and $40 \mathrm{~cm}$ and a layer of $10 \mathrm{~mm}$ of fouling (resin) between 40 and $60 \mathrm{~cm}$. In this way, it is possible to detected different fouling layers in the same tube.

Accelerometer based autonomous fouling detection systems are relatively easy to design and should be preferably implemented at pre-determined duct sections, which are otherwise difficult to access, or exhibit an increased probability for the appearance of fouling. Changes in the response signal can be monitored automatically and continuously, and alarms provided, as soon as critical thickness levels are reached.

With the increase of the fouling, there is a reduction in the frequency values, in the tests with the microphone. It is also observed the different levels of signals along the tube, that make possible to distinguish the layers inside the tube, in other words, clean tube up to $20 \mathrm{~cm}$, tube with $5 \mathrm{~mm}$ of fouling between 20 and $40 \mathrm{~cm}$ and a layer of $10 \mathrm{~mm}$ of fouling (resin) between 40 and $60 \mathrm{~cm}$. In this way, it is possible to detected different fouling layers in the same tube.

\subsection{Tests with a massive duct section}

Supporting experiments have been carried out on a massive duct section, originally mounted in an oil processing plant. Figure 23 presents photography of the experimental setup. The tube was made of carbon steel, with length of $2 \mathrm{~m}$, wall thickness approx. $1 \mathrm{~cm}$, and diameter of $22 \mathrm{~cm}$.

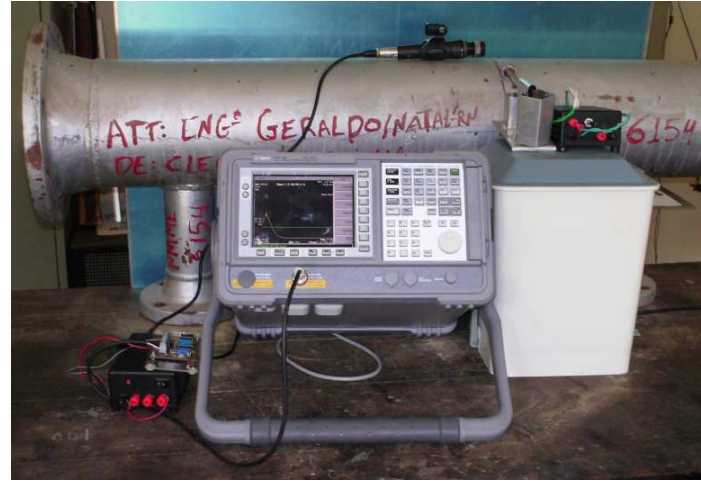

Figure 23: Photography of the experimental setup with a massive duct section.

The obtained results with microphone, in frequency domain, for the tubes without fouling and with $5 \mathrm{~mm}$ of fouling are presented in Figures 24 and 25.

The obtained results with accelerometer, for the tubes without fouling and with $5 \mathrm{~mm}$ of fouling are presented in Figures 26 and 27.

We can observe, once more, a reduction in the frequencies and amplitudes in the monitored signals due the increasing of fouling layer.

In the test with the massive tube, there is no water inside the tube. The reductions in the values of the observed parameters are due to the larger dimensions of the pipe and the impact of the hammer which is the same used for the tests with the smaller tubes. But, the detection of the fouling in the massive tube is still possible in spite of the reduction in the observed parameters.

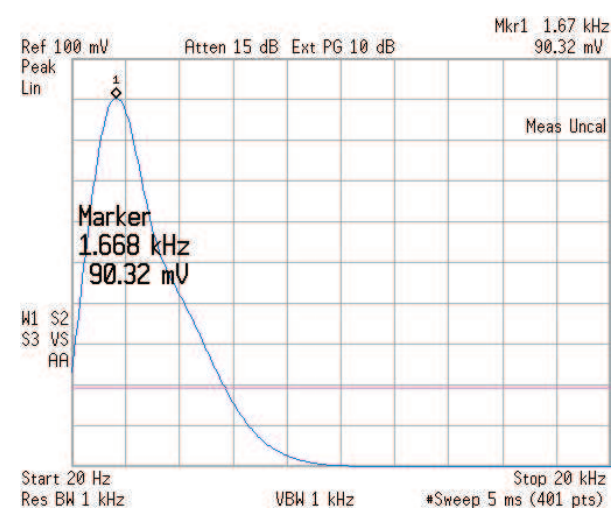

Figure 24: Representation of the microphone output signal for the tube without fouling (massive duct section). 


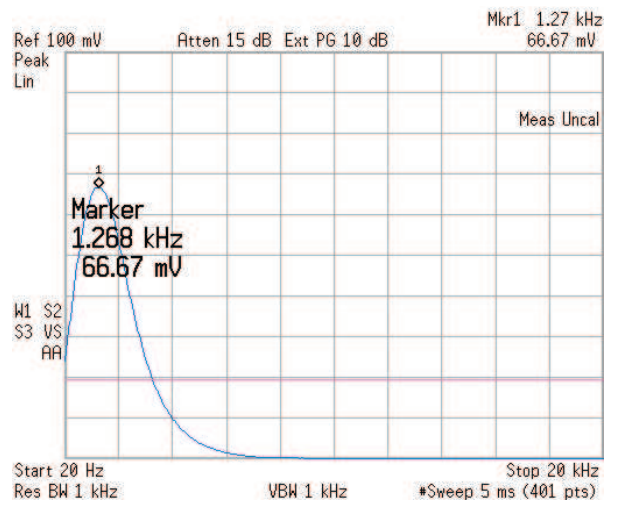

Figure 25: Representation of the microphone output signal for the tube with $5 \mathrm{~mm}$ of fouling (massive duct section).

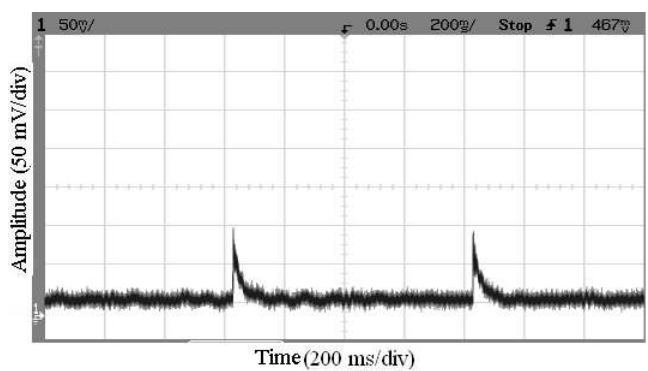

Figure 26: Accelerometer output signals in absence of fouling (massive duct section).

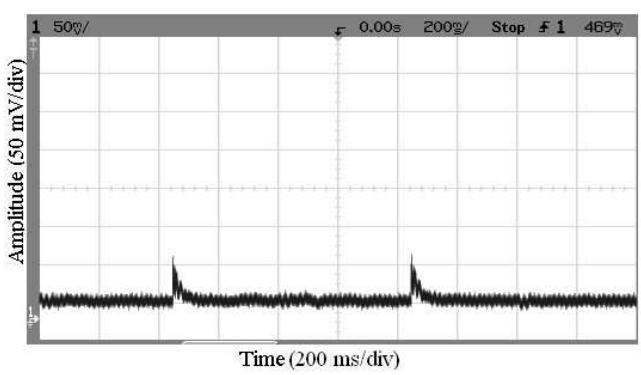

Figure 27: Accelerometer output signals with $5 \mathrm{~mm}$ of fouling (massive duct section).

The amount of fouling can be inferred from the change in frequency/amplitude in an unknown/real tube with fouling, if it is possible to determine the tube signature (tube without fouling). The method also works with joints in pipeline, in this case, once more is necessary to determine the signature in the joints and verify the modifications in the observed signals, as reduction in amplitude and frequency.

\section{CONCLUSIONS}

In this work, a hammer impact test has been employed for fouling detection via vibration tube signatures. This method relies on vibration amplitude and frequency determination using an accelerometer and a microphone.

Variations of amplitude and frequency signatures, resulting from the presence of inner tube fouling layers are easily observed. Absolute values of the output signal can be compared and modifications, as reduction, are clear indications for presence of fouling. Thus, the vibration amplitude and frequency reduction provides important information on the amount of tube fouling.

The hammer impact points in each test have been maintained to assure the same test conditions. The main advantage of the method is the simplicity of the measurements and determination of the parameters; a more sophisticated parameter estimation method was not required, once the values have been determined.

Supporting experiments with a massive duct section of a crude oil plant confirm the practical application of the sensing method.

With the developed techniques, we can evaluate different points of the pipes and identify the places with larger or smaller fouling thickness, by analyzing the modifications in the parameters (amplitude, frequency and decay time) in each test. As result, the costs with maintenance are reduced, and the monitoring processes in the pipe systems are improved.

\section{ACKNOWLEDGMENTS}

The authors would like to thanks CNPq and CAPES for financial support in this project.

\section{REFERENCES}

Ahn, S. J. and Jeong, W. B. (2005). Improvement of impulse response spectrum and its application, Journal of Sound and Vibration. 288(5): 1223-1239.

Barshinger, J. and Rose, J. L. (2002). Guided wave ressonance tuning for pipe inspection, Journal of Pressure Vessel Technology 124(3): 303-310.

Branco, V. A. M., Mansoori, G. A., Xavier, L. C. A., Park, S. J. and Manafi, H. (2001). Asphaltene floculation and collapse from petroleum fluids, Journal of Petroleum Science and Engineering 32(4): 217230. 
Cam, E., Lei, M., Kocaarslan, I. and Taplamacioglu, C. (2002). Defect detection in a cantilever beam from vibration data, Technical report, Kirikkale University, Faculty of Engineering, Department of Electrical and Electronics, Kirikkale.

Carino, N. J. (2001). The impact-echo method: An overview, Proceedings of the Structures Congress and Exposition, Washington, USA.

Castelline, P., Revel, G. M. and Scalise, L. (2004). Measurement of vibrational modal parameters using laser pulse excitation techniques, Measurement 35(2): 163-179.

Champoux, Y., Cotoni, V., Paillard, B. and Beslin., O. (2003). Moment excitation of structures using two synchronized impact hammers, Journal of Sound and Vibration 263(3): 515-533.

Escobeto, J., Mansoori, G. A., Balderas-Joers, C., Carranza-Becerra, L. J. and Mendes-Garcia, M. A. (1997). Heavy organic deposition during oil production from a hot deep reservoir: A field experience, Proceedings of the 5th Latin American and Caribbean Petroleum Engineering Conference and Exhibits, Rio de Janeiro, Brazil.

Gatts, C. E. N., Siqueira, M. H. S., da Silva, R. R. and Rebello, J. M. A. (2004). The use of ultrasonic guided waves and wavelets analysis in pipe inspection, Ultrasonics 41(10): 785-797.

Hay, T. R. and Rose, J. L. (2002). Fouling detection in the food industry using ultrasonic guided waves, Journal of Food Control 14(7): 481-488.

Krisher, A. S. (2003). Technical information regarding coupon testing, Technical report, ASK Associates, St. Louis, Missouri.

Lohr, K. R. and Rose, J. L. (2002). Ultrasonic guided wave and acoustic impact methods for pipe fouling detection, Journal of food engineering, Elsevier Science 56(4): 315-324.

Mansoori, G. A. (1997). Modeling of asphaltene and other heavy organics depositions, Journal of Petroleum Science and Engineering 17: 101-111.

Mansoori, G. A. (2001). Deposition and fouling of heavy organic oils and other compounds, 9th International Conference on Properties and Phase Equilibria for Product and Process Design, Okayama, JAPAN.
Nahvi, H. and Jabbari, M. (2005). Crack detection in beams using experimental modal data and finite element model, International Journal of Mechanical Sciences 47(10): 1477-1497.

Panchal, C. B. (1997). Fouling mitigation of industrial heat exchange equipment, Technical report, Bengell House, New York.

Rose, J. L. (1995). Recent advances in guided wave nde, Proceedings on IEEE Ultrasonic Symposium 1: 761-770.

Roy, P. K. and Ganesan, N. (1995). Transient response of a cantilever beam subject to on impulse load, Journal of Sound and Vibration 183(5): 873-880.

Shen, M. H. H. and Pierre, C. (1994). Free vibrations of beams with a single-edge crack, Journal of Sound and Vibration 170(2): 237-259.

Silva, J. J. (2008). Development of Foulinng Detection Techniques Using Non-invasive Methods, $\mathrm{PhD}$ thesis, (In portuguese), Federal University of Campina Grande, Campina Grande, Brazil.

Silva, J. J., Lima, A. M. N., Neff, F. H. and Neto, J. S. R. (2009a). Non-invasive fast detection of internal fouling layers in tubes and ducts by acoustic vibration analysis, IEEE Transactions on Instrumentation and Measurement 58(1): 108-114.

Silva, J. J., Lima, A. M. N., Neff, F. H. and Neto, J. S. R. (2009b). Vibration analysis based on hammer impact test for multilayer fouling detection, XIX IMEKO World Congress Fundamental and Applied Metrology, OLisbon, Portugal.

Silva, J. J., Lima, A. M. N., Neff, F. H. and Neto, J. S. R. (2010a). Aplicação do teste de impacto do martelo para detecção de incrustação em tubulações, XVIII Congresso Brasileiro de Automática, Mato Grosso, Brasil.

Silva, J. J., Lima, A. M. N., Neff, F. H. and Neto, J. S. R. (2010b). Vibration analysis based on hammer impact for fouling detection using microphone and accelerometer as sensors, Sensors and Transducers Journal 112(1): 10-23. 